\title{
Intenção de rotatividade e percepção de suporte organizacional em um órgão público federal
}

\author{
Larissa Coutinho Diógenes \\ Universidade de Brasília (UnB)
}

Tatiane Paschoal

Universidade de Brasília (UnB)

Elaine Rabelo Neiva

Universidade de Brasília (UnB)

Pedro Paulo Murce Meneses

Universidade de Brasília (UnB)

Este estudo testou a influência do suporte organizacional percebido na intenção de rotatividade de servidores públicos efetivos de um órgão da administração pública federal. O referencial teórico aponta mudanças e tendências na administração pública brasileira e aborda a intenção de rotatividade como a probabilidade de o trabalhador deixar a organização em um futuro próximo. Um total de 112 servidores preencheu um questionário composto por medidas validadas no Brasil. Foram conduzidas análises estatísticas descritivas, correlações bivariadas e regressão hierárquica. Os resultados descritivos revelaram que os servidores têm um alto desejo de deixar a organização e avaliam negativamente o suporte organizacional voltado à ascensão, promoção e salários e o suporte organizacional voltado à gestão do desempenho. Os resultados da regressão múltipla hierárquica indicaram que quanto menor é a percepção de suporte organizacional, maior é a intenção de rotatividade. Além disso, idade e tempo na organização também influenciaram a intenção de rotatividade. Os resultados estimulam a discussão sobre práticas e políticas de recursos humanos e valorização no serviço público.

Palavras-chave: rotatividade, serviço público, comportamento organizacional, saúde organizacional, gestão de pessoas, administração federal

[Artigo recebido em 20 de novembro de 2014. Aprovado em 21 de outubro de 2015.] 


\section{Intención de turnover y apoyo organizacional en una organización pública federal}

Este estudio puso a prueba la influencia del apoyo organizacional sobre la intención de turnover de servidores públicos de puestos permanentes de una organización pública federal. El referencial teórico señala cambios y tendencias en la Administración Pública brasileña y contempla la intención de turnover como la probabilidad del trabajador dejar la organización en un futuro próximo. Un total de 112 servidores contestaron a un cuestionario que contenía medidas validadas en Brasil. Se han realizado análisis estadísticos descriptivos, correlaciones bivariadas y regresiones jerárquicas. Los resultados descriptivos mostraron que los servidores tienen un fuerte deseo de dejar la organización y evaluan negativamente el apoyo organizacional para ascensión, promoción y remuneración y para la gestión del desempeño. Los resultados de la regressión jerárquica mostraron que cuanto menor es la percepción de apoyo, mayor es la intención de turnover. Además, edad y tiempo en la organizacíon también influenciaron la intención de turnover. Los resultados estimulan la discussión acerca de acciones y políticas de recursos humanos en el servicio público.

Palabras clave: rotación, servicio público, comportamiento organizacional, salud organizacional, gestión de personas, administración federal

\section{Turnover intention and organizational support in a federal governmental organization}

This study tested the influence of organizational support on turnover intention of permanent public servants of a federal governmental organization. Theoretical framework points out changes and trends in Brazilian Public Administration and address the turnover intention as the probability of leaving the organization in the near future. A total of 112 servants answered a questionnaire composed by measures validated in Brazil. Descriptives statistics, bivariate correlations and hierarchical regression were conducted. Descriptives results revealed that servants have a strong desire to leave the organization and evaluate the organizational support for ascension, promotion and salary and performance management in a negative way. Results of hierarchical multiple regression indicated that the lower the perception of organizational support is, the greater the turnover intention is. Furthermore, age and the amount of time in the organization also influenced the turnover intention. Results stimulate the discussion about resource management practices and politics in the public service.

Keywords: turnover, public service, organizational behavior, organizational health, people management, federal administration 


\section{Introdução}

As pressões e demandas sociais, econômicas e tecnológicas, aliadas à crescente exigência pela qualidade dos bens e serviços públicos e aos novos modelos de gestão adotados na administração pública em diferentes países, têm estimulado os pesquisadores do campo do comportamento organizacional e da gestão pública a incluírem a temática do elemento humano no trabalho e do vínculo entre servidor e organização em suas agendas (PerRY; HondegheM; WISE, 2010; VANDENABeEle, 2007). Existe consenso na literatura de que a qualidade do serviço público depende, entre outros fatores, da capacidade dos governantes atraírem, contratarem e manterem profissionais competentes e motivados com os seus postos de trabalho (LEWIS; FRANK, 2002; PERRY, 1996).

Assim, identificar e compreender comportamentos ou intenções de comportamentos dos servidores públicos em seu trabalho se revela uma demanda central para a atuação dos gestores do setor em questão, especialmente se considerado o momento de transformações pelas quais a administração pública no País vem passando. De acordo com o Ministério do Planejamento, Orçamento e Gestão - MPOG (2012), o instrumento do concurso público federal foi intensificado a partir de 2003, com vistas à profissionalização da máquina pública, bem como recuperação da força de trabalho perdida em razão de aposentadorias, evasão e substituição de trabalhadores terceirizados.

O período de 2003 a 2010 foi, assim, marcado pela expansão do quadro de servidores públicos selecionados por meio de concurso (JúNIOR; NOGUEIRA, 2011). No entanto, apesar de o crescimento econômico dos últimos anos ter favorecido o aumento de contratações do setor privado e a ampliação do quadro de pessoal da administração pública, um dos maiores desafios no mercado de trabalho atual consiste em controlar as altas taxas de rotatividade de mão de obra, pois, ao mesmo tempo em que ocorre um grande número de contratações, há um número expressivo de desligamentos (DEPARTAMENTO INTERSINDICAL DE ESTATísTICA E ESTUDOS SOCIOECONÔMICOS, 2011).

Verleun (2008) destaca que a rotatividade de servidores públicos entre as diversas carreiras dos três poderes e das três esferas de governo é relativamente alta e sazonal. Dados do MPOG (2012) apontam que muitos são os candidatos aprovados em concurso público que não se apresentam para a nomeação ou que tomam posse e, em seguida, pedem exoneração ainda dentro do prazo de validade do concurso, que, por regra, é de seis meses a dois anos, prorrogável pelo mesmo período, conforme determina o artigo 12 da Lei no 8.112/1990 (BRASIL, 1990).

A alta rotatividade afeta negativamente o funcionamento e produtividade do serviço público, pois são necessários tempo e recursos para a realização de um novo 
processo seletivo, a fim recrutar pessoas aptas para repor a força de trabalho e, posteriormente, gastos com treinamento e capacitação. Cabe ressaltar ainda que, além dos custos financeiros, a saída voluntária de servidores pode ocasionar quebra do fluxo de trabalho e até mesmo perda de historicidade da organização (FERREIRA; FREIRE, 2001).

As causas que levam um indivíduo a sair, por vontade própria, da organização em que trabalha podem estar associadas tanto a fatores pessoais, como metas, valores, mudanças e questões particulares do trabalhador, quanto a fatores da própria organização, como remuneração, plano de carreira, tipo de contrato, relações socioprofissionais, entre outros (AlLEN; SHANOCK, 2013; DE GIETER; HOFMANS, 2015; Regts; Molleman, 2012; YANG; TReadwaY; StepinA, 2013). No âmbito do serviço público, as disparidades de remuneração existentes entre as três esferas do Poder - Executivo, Legislativo e Judiciário -, conforme propõe Verleun (2008), podem fazer com que um servidor, mesmo depois de ter concorrido com diversos outros candidatos e sido aprovado no processo seletivo, tenha o desejo de sair do local em que trabalha em busca de oportunidades de crescimento profissional em outros órgãos, dado que nem todas as organizações da administração pública possuem planos de carreira ou mesmo políticas de valorização do servidor efetivamente estruturadas e consolidadas.

O cenário exposto estimula a investigação sobre as variáveis que podem levar os trabalhadores a desejarem sair da sua organização, a fim de evitar que esse desligamento ocorra de forma efetiva, considerando-se os efeitos negativos que tal comportamento pode ocasionar na organização. Explorar as relações entre o suporte organizacional e o desejo de deixar a organização, por exemplo, pode ser uma ferramenta útil para auxiliar na compreensão da rotatividade. O suporte organizacional envolve a percepção dos trabalhadores sobre as principais práticas organizacionais, como aquelas dirigidas ao desempenho, às condições materiais, às recompensas e crescimento na carreira e à carga e organização do trabalho. O diagnóstico da percepção dos trabalhadores sobre o suporte da organização, portanto, oferece um amplo panorama do contexto de trabalho (EISENBERGER et al., 1986; Oliveira-Castro; Pilati; Borges-AndRade, 1999).

Este estudo teve como objetivo testar a influência do suporte organizacional percebido sobre a intenção de rotatividade de servidores públicos pertencentes ao Plano Geral de Cargos do Poder Executivo (PGPE) de um órgão da administração pública federal. Trata-se de um estudo teórico-empírico, com emprego de survey para levantamento de dados, abordagem quantitativa e recorte transversal. A sessão seguinte apresenta o referencial teórico que embasou o estudo. Na sequência, são fornecidas as informações sobre o método adotado para alcançar os objetivos propostos. Os resultados encontrados são, por fim, apresentados e discutidos. 


\section{Referencial teórico}

A administração pública brasileira vivenciou grandes transformações nas últimas décadas no que tange às expectativas e ações de modernização de seu aparato administrativo (MOTTA, 2007). Especialmente a partir da década de 1980, o Brasil tem passado por diversas fases de reforma da administração pública, e a ênfase dada à gestão de pessoas diferenciou-se a cada governo (ORGANIZAÇÃo PARA A COOPERAÇÃo E DESENVOLVIMENTO ECONÔMICO, 2011).

Durante muito tempo, a ocorrência de práticas clientelistas e patrimonialistas permeou os modos de gestão do setor público, observando-se a existência de sistemas de loteamentos políticos, firmados para manter coalizões de poder e atender a grupos preferenciais (MOTTA, 2007). O ingresso no serviço público firmava-se, basicamente, por meio de arranjos políticos ou administrativos, gerando um entrave para a construção de um Brasil moderno e dificultando o alcance da profissionalização da administração pública (FARIAS; GAETANI, 2002).

Frente ao cenário clientelista e patrimonialista, a adoção de uma burocracia profissionalizada traria a maximização da eficiência alocativa dos recursos públicos para o Estado, uma vez que reduziria a probabilidade de esse ser capturado por grupos de interesse (VERLEUN, 2008). O fim do período militar marcou o início do processo recente de reforma do Estado (ABRUCIO, 2007) e evidenciou a ruptura com as antigas formas de estruturação do setor público, uma vez que o clientelismo deixou de ser o critério dominante de contratação (FARIAS; GAETANI, 2002). A promulgação da Constituição de 1988 abarcou as mudanças mais significativas na reforma do serviço civil, ao restabelecer os valores tradicionais de mérito, continuidade e probidade (OrganizaçÃo PARA A CoOPERAÇÃo E DESEnVolvimento ECONÔMICO, 2011), por meio da introdução de dispositivos que transformavam a quase totalidade das formas de emprego público em serviço público estatutário (FARIAS; GAETANI, 2002), instituindo, assim, o princípio da seleção meritocrática e universal por meio de concurso público (ABRUCIO, 2007). Pode-se destacar o inciso II do artigo 37 da referida Constituição (BRASIL, 1988), o qual dispõe que "a investidura em cargo ou emprego público depende de aprovação prévia em concurso público de provas ou de provas e títulos, de acordo com a natureza e a complexidade do cargo ou emprego (...)". Dessa forma, o indivíduo que ingressar nos quadros funcionais da administração pública por meio de concurso para ocupar um cargo público será denominado servidor público, conforme determina o artigo 2o da Lei no 8.112/1990 (BRASIL, 1990).

Essas medidas repercutiram de tal forma que, atualmente, a admissão na maioria das posições do serviço público requer a aprovação em um concurso, fato que tem deixado pouco espaço para o patronato (ORGANIZAÇÃo PARA A COOPERAÇÃo E DESENVOLVIMENTO ECONÔMICO, 2011). A partir de 1995, houve a realização de um 
número considerável de concursos, bem como a revitalização das atividades de capacitação desenvolvidas pela Escola Nacional de Administração Pública (Enap), incentivadas durante a gestão do Presidente Fernando Henrique Cardoso, pelo então Ministro Bresser Pereira (ABRUCIO, 2007). Bresser Pereira, amparado na ideia de uma administração voltada para resultados, liderou a reforma administrativa em que a profissionalização constituía-se parte da agenda de prioridades do Poder Executivo (FARIAS; GAETANI, 2002). Tais medidas e ações evidenciavam a ênfase dada à meritocracia no serviço público brasileiro (ABRUCIO, 2007).

Contudo, o contexto de séria crise cambial, presente no segundo mandato do Governo Fernando Henrique Cardoso, ensejou restrições aos gastos com recursos humanos, que se sobrepuseram às propostas de modernização do aparato administrativo. A admissão de novos servidores no período foi mínima, até mesmo para as carreiras essenciais de Estado, que constituíam foco do plano da reforma administrativa. Essa situação se modificou com o crescimento econômico iniciado no ano de 2004, o qual favoreceu a decisão de reabertura dos concursos públicos dirigidos para pessoal permanente e temporário em áreas prioritárias (JúNIOR; Nogueira, 2011).

Segundo Júnior e Nogueira (2011), observou-se, então, a expansão do quadro de pessoal da administração federal, e, aproximadamente, 155 mil novos servidores foram admitidos entre 2003 e 2010. Mais especificamente no contexto do Poder Executivo, dados do Ministério do Planejamento, Orçamento e Gestão - MPOG (2012) apontam que 30.234 trabalhadores, entre 1995 e 2010, ingressaram no serviço público por meio de concurso para ocupar cargos do Plano Geral de Cargos do Poder Executivo (PGPE), nos três níveis de escolaridade.

É possível notar que "a instituição do concurso público para provimento de cargos no aparelho do Estado Brasileiro tem se constituído num forte atrator de recursos humanos" (CASTELAR et al., 2010, p. 82). Os referidos autores destacam que o interesse dos indivíduos em fazer parte do quadro de funcionários da administração pública decorre da existência de fatores como: maior segurança quanto à permanência no emprego frente à possibilidade de atingir a estabilidade no cargo; salários atraentes quando comparados aos de níveis semelhantes na iniciativa privada; benefícios indiretos, como plano de saúde e de previdência diferenciados.

Farias e Gaetani (2002) defendem que a entrada de profissionais concursados na administração pública federal tem alterado positivamente a dinâmica de funcionamento dos órgãos em que trabalham. Júnior e Nogueira (2011) afirmam que a escolha de servidores a partir de critérios meritocráticos, especialmente para a execução de atividades-fim dos órgãos, indicaria possibilidade de maior impacto positivo sobre a produtividade agregada do setor público. Além disso, quando os servidores assumem a forma de vinculação estatutária, esses estão sob direitos e 
deveres comuns e estáveis, o que poderia gerar "mais coesão e homogeneidade no interior da categoria, aspecto considerado essencial para um desempenho satisfatório do Estado em longo prazo" (JúNIOR; NogUEIRA, 2011, p. 239).

Pesquisadores e gestores organizacionais convergem quanto à importância da profissionalização da administração pública e dos servidores públicos para a melhora do desempenho e da atuação do Estado. Conforme propõe Gomes (2008), os servidores são os agentes que atuam direta ou indiretamente para atender às necessidades dos cidadãos, por meio da viabilização de ações e implementação das políticas de gestão do governo. A constatação de Verleun (2008) e dos Boletins Estatísticos do MPOG (2012) sobre a alta rotatividade entre servidores públicos convida pesquisadores e gestores a investigar, de forma mais sistemática, as principais causas do fenômeno e as possíveis ações e estratégias para contornar o problema.

O presente estudo visa contribuir para a discussão e compreensão do problema exposto a partir das variáveis intenção de rotatividade e suporte organizacional. Assim, as definições e orientações teóricas adotadas para cada variável são apresentadas.

\section{Intenção de rotatividade}

Segundo Mobley (1992, p. 30), a rotatividade no trabalho consiste na "suspensão da condição de membro participante de uma organização por parte de um indivíduo que recebia compensação monetária desta". Para o referido autor, a rotatividade pode ser involuntária ou voluntária. A primeira trata do desligamento do trabalhador por iniciativa da organização - podendo ocorrer nos casos de substituições com o intuito de melhorar o potencial humano existente e atender as demandas econômicas e financeiras do ambiente externo -, bem como se refere a casos de aposentadoria e falecimento. A rotatividade voluntária, por sua vez, ocorre quando o funcionário decide deixar a organização por iniciativa própria (MOBLEY, 1992). Esse tipo de rotatividade pode representar a perda de colaboradores essenciais, culminando em prejuízo ao funcionamento organizacional.

O presente estudo focaliza a intenção de rotatividade do servidor. Segundo Vandenberg e Nelson (1999), esse fenômeno consiste na probabilidade subjetiva, própria dos indivíduos, de deixar a organização em um futuro próximo, de tal maneira que o simples desejo configura o que se chama intenção de rotatividade. $A$ importância da intenção de rotatividade na investigação da rotatividade de pessoal justifica-se porque a intenção pode afetar diretamente o desligamento efetivo (FERREIRA; SIQUeIRA, 2005). Tanto as pesquisas acadêmicas quanto as experiências corporativas sugerem uma forte relação entre funcionários que expressam intenção de sair e aqueles que realmente deixam a organização (MOBLEY, 1992; WINTERTON, 2004). A intenção de rotatividade, portanto, pode preceder um desligamento efetivo. 
Para Mobley (1992), a estimativa periódica das intenções de comportamento de saída constitui uma abordagem bastante recomendada para os gestores nas organizações. No âmbito acadêmico, nem sempre é possível acessar uma amostra representativa de trabalhadores que deixaram a organização, a fim de verificar os antecedentes pessoais e organizacionais do comportamento. Além disso, entrevistas de desligamento costumam não fornecer informações suficientes e fidedignas sobre antecedentes do comportamento, pois o trabalhador pode não se interessar em contribuir com informações para a organização ou prefere não levantar discussões sobre questões que não farão mais parte da sua vida. Vale ressaltar que compreender e diagnosticar a intenção de rotatividade permite ao gestor desenvolver políticas e práticas para manter os trabalhadores estratégicos ou competentes antes que eles deixem seus postos de trabalho.

Pesquisas empíricas, como a de Hausknecht, Rodda e Howard (2009), sugerem possíveis antecedentes para a rotatividade. Os referidos autores investigaram as razões relatadas por quase 25 mil empregados da indústria hospitalar e de lazer para não deixarem a organização em que trabalhavam. Recompensas extrínsecas, prestígio social da organização, comprometimento e satisfação no trabalho foram os principais preditores para o desejo de permanecer na organização. Ramlall (2003), por sua vez, coletou dados com 78 respondentes que haviam deixado seu trabalho e identificou que satisfação com o cargo, identificação com a tarefa, feedback sobre o resultado do trabalho e número de promoções alcançadas na organização foram os preditores mais significativos da decisão de buscar emprego em outras organizações.

De Gieter e Hofmans (2015) verificaram a influência de recompensas financeiras, materiais e psicológicas na intenção de rotatividade de 179 empregados do setor privado. Além disso, os referidos autores sugerem que variáveis pessoais, como valores do trabalho e características sociodemográficas, podem moderar a relação entre as variáveis. Em estudo conduzido com 149 enfermeiros, Regets e Molleman (2012) indicaram o efeito de variáveis como comportamentos de cidadania organizacional dos colegas e a satisfação no trabalho sobre a intenção de rotatividade. Yang et al. (2013) conduziram estudo de campo com 782 empregados do setor de serviços e identificaram um efeito mediador da justiça de procedimento e das políticas organizacionais na influência do conflito e da ambiguidade de papel sobre a intenção de rotatividade.

No âmbito das organizações públicas, estudos empíricos são mais escassos. Na literatura internacional, Caillier (2011) testou um modelo de preditores para a intenção de rotatividade entre servidores federais norte-americanos. Os resultados revelaram que a intenção de sair da organização era menor entre servidores mais satisfeitos, com maior motivação para o serviço público e que apresentavam desempenho mais elevado. Moynihan e Landuyt (2008) e Kim (2005) verificaram que 
a participação do trabalhador nas decisões organizacionais estava negativamente relacionada à intenção de rotatividade. Vínculos do trabalhador com a organização, motivação para o serviço público, perfil profissiográfico e características do contexto de trabalho são variáveis comumente investigadas como possíveis preditores da intenção de rotatividade em organizações públicas. Caillier (2008) alerta, porém, para peculiaridades e divergências entre os resultados desses estudos e salienta a necessidade de esforços mais sistemáticos para a compreensão do fenômeno.

No Brasil, apesar da importância da temática, poucos estudos empíricos foram encontrados na literatura científica. Ferreira e Siqueira (2005) testaram um modelo explicativo para intenção de rotatividade que incluiu comprometimento organizacional afetivo e satisfação no trabalho como antecedentes diretos e percepção de justiça de remuneração como antecedente indireto. $O$ estudo foi conduzido em empresas paulistas e sustentou o modelo proposto, revelando que quanto maior é o comprometimento, a satisfação no trabalho e a percepção de justiça, menor é a intenção de rotatividade. Ferreira e Freire (2001) investigaram a inter-relação entre carga de trabalho e a ocorrência da alta rotatividade de pessoal no contexto sociotécnico de postos de abastecimento de combustível. Os resultados apontam que a organização estudada apresenta como característica marcante orientação tecnocêntrica e filiação ao pensamento taylorista, lógica que norteia o trabalho prescrito e idealiza um frentista de múltiplos papéis, frequentemente controlado por ferramentas de desempenho e ameaçado constantemente de punições. Os autores concluíram que a falência das estratégias operatórias, os esforços permanentes para conduzir as diversas exigências, aliados aos baixos salários, tornam insustentável a permanência dos frentistas na função, culminando assim em uma rotatividade constante.

Ainda no contexto nacional, Campos e Malik (2008) pesquisaram a rotatividade de médicos generalistas do Programa Saúde da Família (PSF), no Município de São Paulo. A distância entre as unidades de atendimento e a disponibilidade de materiais foram os fatores que mais apresentaram correlação com a rotatividade. Medeiros et al. (2010), por sua vez, pesquisaram as causas da rotatividade entre médicos e enfermeiros das equipes da Estratégia de Saúde da Família, no Vale do Taquari (RS). Os resultados sugeriram a precarização do vínculo de trabalho, a fragmentação da formação, o estilo de gestão autoritário, a ausência de vínculo com a comunidade e as más condições de trabalho como principais causas de rotatividade.

Ferreira e Freire (2001) destacam que as causas da rotatividade são múltiplas. A ampla compreensão do fenômeno depende das pesquisas e diagnósticos conduzidos nas diferentes organizações e com diversos perfis de trabalhadores. Se, no setor privado, uma quantidade razoável de estudos pode ser encontrada, no âmbito da administração pública federal, apesar da alta rotatividade observada (MPOG, 
2012), poucas pesquisas empíricas são conduzidas. O presente estudo pretende contribuir para o preenchimento dessa lacuna, buscando descrever a intenção de rotatividade entre servidores e testando a existência de relações com a percepção de suporte organizacional. O suporte, que consiste em uma variável organizacional percebida, tem se revelado um importante preditor de comportamentos diversos no trabalho, explicando elevada variância de variáveis comportamentais no contexto organizacional (OliveIRA-CASTRO et al., 1999; PASCHOAL; TORRES; PORTO, 2010).

\section{Percepção de suporte organizacional}

O suporte organizacional tem sido considerado um importante preditor de variáveis como desempenho no trabalho, comprometimento e cidadania organizacional (OliveIRA-CASTRo et al., 1999; RHOADES; EISENBERGER, 2002). Mais recentemente, pesquisas têm verificado a forte relação do suporte com bem-estar, estresse e burnout do trabalhador (PASCHOAL; TORRES; PORTO, 2010; OLIVEIRA; TRISTÃO; NEIVA, 2006). Segundo Eisenberger et al. (1986) e Oliveira-Castro et al. (1999), a percepção de suporte organizacional consiste nas crenças que os trabalhadores formulam sobre o quanto a organização valoriza e retribui seus esforços pessoais e se preocupa com seu bem-estar pessoal. Basicamente, o fenômeno envolve as percepções do trabalhador acerca da qualidade do tratamento que recebe da organização em retribuição ao esforço que despende no trabalho.

Em estudo sobre a estrutura da percepção de suporte organizacional no Brasil, Oliveira-Castro et al. (1999) identificaram quatro dimensões do construto. A primeira, gestão de desempenho, refere-se à opinião dos trabalhadores sobre as práticas organizacionais de gerenciamento do desempenho do funcionário, como estabelecimento de metas, valorização de novas ideias, conhecimento de dificuldades associadas à execução eficaz das tarefas e esforço organizacional de atualização de seus colaboradores em face das novas tecnologias e processos de trabalho. A segunda dimensão é a carga de trabalho e refere-se às exigências e à sobrecarga de tarefas atribuídas aos funcionários. O suporte material, terceira dimensão, referese à percepção da disponibilidade, adequação, suficiência e qualidade dos recursos materiais e financeiros fornecidos pela organização para apoiar a execução eficaz das tarefas, bem como os esforços organizacionais de modernização e dinamização dos processos de trabalho e qualificação da mão de obra interna. Por fim, a dimensão de suporte para práticas de ascensão, promoção e salários diz respeito às práticas organizacionais de retribuição financeira, promoção e ascensão funcionais.

Pesquisas diversas sugerem a importância da percepção de variáveis organizacionais e laborais para a predição da rotatividade (CAMPOS; MALIK, 2008; Ferreira; SiqueIRA, 2005; Medeiros et al., 2010; RAMLALL, 2003). Eisenberger et 
al. (2002) verificaram que o suporte organizacional é um importante mediador do impacto de ações de agentes específicos da organização, como os supervisores, na retenção de empregados. Allen e Shanock (2013) conduziram um estudo de campo e longitudinal com 500 empregados do setor privado no seu primeiro ano de trabalho em suas organizações e verificaram que as práticas de socialização influenciam a percepção de suporte organizacional e que essa variável, por sua vez, influencia a rotatividade do trabalhador.

Conforme aponta Eisenberger et al. (2002), a percepção de suporte organizacional está embasada na ideia de retribuição organizacional aos esforços do trabalhador, ou seja, relaciona-se ao grau em que as ações organizacionais são ou não percebidas como valorização e recompensa oferecida pelos esforços individuais. O fenômeno do suporte organizacional situa-se num contexto de interação dos interesses organizacionais com os interesses do trabalhador. Organização e funcionário envolvem-se numa parceria, na qual cada uma das partes apresenta exigências e demandas próprias. A organização estabelece demandas quanto ao desempenho, aos resultados e às normas de comportamentos. Em troca, os funcionários esperam receber as condições e retribuições necessárias para a realização de tarefas. Esses retornos organizacionais são essenciais para a execução do trabalho e para o adequado desempenho do trabalhador.

O funcionário aporta ao trabalho suas habilidades, seus conhecimentos, suas experiências e motivação, e, se não encontrar meios de satisfazer suas expectativas, ele não se sentirá em uma relação de troca, mas de exploração, podendo manifestar desejo, ou mesmo comportamento, de deixar seu posto de trabalho e buscar outra organização. Assim, explorar possíveis relações entre a percepção de suporte organizacional e a intenção de rotatividade de servidores desponta como um problema de pesquisa relevante em um contexto pouco compreendido e investigado de forma sistemática.

\section{Método}

Nesta seção, são apresentados os seguintes tópicos: caracterização da organização investigada; caracterização da população e amostra; descrição dos instrumentos de pesquisa; descrição dos procedimentos de coleta e análise de dados.

\section{Caracterização da organização}

A pesquisa foi realizada em um órgão público federal, pertencente à administração direta da União, conforme disposto na Lei no 10.683, de 28 de maio de 2003. Para não identificá-lo, serão omitidos: nome, informações sobre sua estrutura e história. 0 quadro de pessoal permanente do órgão é composto por 2.849 servidores públicos, 
conforme dados de fevereiro de 2012 do Boletim Estatístico de Pessoal do MPOG. Desconsiderando-se as autarquias e empresas públicas a ele vinculadas, existem 809 cargos de nível médio e superior, classificados no Plano Geral de Cargos do Poder Executivo (PGPE). Dos 809 cargos existentes, atualmente apenas 348 estão ocupados.

Cumpre destacar que, no último concurso, realizado em 2009, foram abertas 293 vagas. Um total de 574 candidatos foram classificados e nomeados para somar-se aos servidores já existentes. No entanto, até a data de 22 de março de 2011, na qual foi realizada a última atualização relativa às nomeações do referido concurso, haviam ocorrido 33 exonerações, 61 vacâncias, 64 desistências e outros 145 servidores foram nomeados e não tomaram posse. Dados fornecidos pela Coordenação-Geral de Recursos Humanos informam que a somatória de todo o período, desde o início das nomeações em 2009, até o mês de agosto de 2012, foi de 138 vacâncias e exonerações, 26 servidores cedidos a outros órgãos, 19 servidores em exercício provisório em autarquia vinculada ao órgão e 216 servidores nomeados no referido concurso que não tomaram posse.

Considerando que a admissão no serviço público ocorre em intervalos de tempo consideravelmente longos e que os dados descritos acima demonstram que mais da metade dos candidatos nomeados já deixou o órgão, evidencia-se a necessidade de investigar e monitorar os possíveis fatores que possam levar ao surgimento do desejo dos servidores que ainda fazem parte de seu quadro de pessoal a deixar a organização em algum ponto futuro.

\section{População e amostra}

Foram enviados questionários ao e-mail institucional de todos os 348 servidores pertencentes ao PGPE vinculados ao órgão investigado. Desses, 112 foram respondidos e retornados pelos servidores que estavam no exercício de suas funções, o que equivale a $32,18 \%$ do total de servidores pertencentes ao PGPE.

Utilizando o tamanho da amostra - 112 respondentes - e o número de preditores do modelo a ser testado (quatro fatores de suporte organizacional), foi calculado o poder do teste para regressão linear múltipla por meio do programa G-Power 3.1 (FAUL et al., 2007). Foi considerado um nível de significância ( $\alpha$ ) de 0,05 e um efeito do tamanho da população (ES) de 0,15. O poder do teste foi de 0,91.

Em relação ao perfil da amostra, 58,93\% dos respondentes são do sexo feminino. A média de idade foi de 33,08 anos (DP = 5,74), variando de 21 a 65 anos; e o tempo de serviço no órgão foi de 4 anos ( $D P=9,38$ ). No que tange ao cargo, $56,25 \%$ da amostra ocupa cargo de nível médio e $43,75 \%$, cargo de nível superior. Já em relação ao grau de escolaridade, $4,46 \%$ da amostra têm ensino médio completo, $22,32 \%$ possuem ensino superior incompleto, $42,86 \%$ têm ensino superior completo, 28,57\% possuem pós-graduação e 0,89\% possuem mestrado e doutorado. 


\section{Instrumentos}

Foi aplicado um questionário composto pelos seguintes instrumentos: escala de suporte organizacional percebido (Esop) e escala de intenção de rotatividade (EIR). A escala de suporte organizacional percebido (Esop), validada por Tamayo et al. (2000), é composta de 23 itens divididos em quatro fatores: gestão organizacional do desempenho, com seis itens e confiabilidade ( $\alpha$ de Cronbach) de 0,69; sobrecarga de trabalho, com cinco itens e $\alpha$ igual a 0,84; percepção de suporte material, com sete itens e $\alpha$ de 0,84 ; política de pagamento e desenvolvimento, referente à percepção de ascensão, promoção e salários, composto por cinco itens e $\alpha$ de 0,77. A escala de resposta é do tipo Likert, composta por cinco pontos, variando de 1 (nunca) a 5 (sempre).

O segundo instrumento utilizado foi a escala de intenção de rotatividade (EIR), desenvolvida por Siqueira et al. (1997). É composta por três itens e confiabilidade $\alpha$ de 0,95 . Por meio de uma escala tipo Likert de cinco pontos, variando de 1 (nunca) a 5 (sempre), os respondentes indicam a frequência com que planejam sair da organização.

\section{Procedimento de coleta e análise de dados}

Considerando que o órgão exerce suas atividades em vários estados brasileiros e que é composto por diversos funcionários, como terceirizados, comissionados, servidores de outros órgãos que estão cedidos e servidores do próprio quadro pertencentes a planos de carreira distintos do PGPE, constatou-se um entrave para a aplicação do instrumento de pesquisa in loco, devido à dificuldade de acesso apenas aos servidores que constituíam a população-alvo deste estudo.

Dessa forma, optou-se pela utilização de um formulário eletrônico confeccionado na plataforma eletrônica Google Docs, o qual foi enviado ao e-mail institucional dos servidores do PGPE acompanhado de texto explicativo a respeito dos objetivos da pesquisa e instruções para o acesso e preenchimento do questionário. Os dados foram coletados durante o primeiro semestre de 2012.

Quanto à análise de dados, primeiramente, foram realizadas análises estatísticas descritivas das variáveis do estudo. Em seguida, foi realizada uma análise de correlações bivariadas de Pearson para verificar a magnitude e a significância das relações entre a intenção de rotatividade e os fatores de suporte organizacional percebido pelos servidores. A fim de explorar os dados, foram investigadas associações entre variáveis sociodemográficas e a intenção de rotatividade. No caso das variáveis categóricas, como sexo e cargo, foram conduzidas análises de variância nesse sentido. Por fim, utilizou-se regressão múltipla hierárquica para testar o modelo preditivo de intenção de rotatividade. 


\section{Resultados}

Em relação à intenção de rotatividade, e com base em uma escala de frequência de cinco pontos, a pontuação média dos respondentes foi de 4,35 ( $D P=0,93)$, indicando um elevado desejo de sair da organização. A Tabela 1 apresenta os valores das médias e dos desvios-padrão encontrados para intenção de rotatividade e dimensões do suporte organizacional. Além disso, são indicados os valores das correlações bivariadas entre as variáveis.

Tabela 1 - Correlações entre as variáveis do estudo

\begin{tabular}{|c|c|c|c|c|c|c|c|}
\hline Variáveis & $\mathrm{M}$ & $\mathrm{DP}$ & 1 & 2 & 3 & 4 & 5 \\
\hline $\begin{array}{l}\text { 1. Intenção de } \\
\text { rotatividade }\end{array}$ & 4,35 & 0,93 & 1 & & & & \\
\hline $\begin{array}{l}\text { 2. Sobrecarga no } \\
\text { trabalho }\end{array}$ & 3,33 & 0,68 & $0,28 *$ & 1 & & & \\
\hline 3. Suporte material & 3,16 & 0,62 & $-0,32 *$ & $-0,39 *$ & 1 & & \\
\hline $\begin{array}{l}\text { 4. Gestão de } \\
\text { desempenho }\end{array}$ & 2,65 & 0,67 & $-0,40 *$ & $-0,36 *$ & $0,65^{*}$ & 1 & \\
\hline $\begin{array}{l}\text { 5. Ascensão, promoção } \\
\text { e salários }\end{array}$ & 1,63 & 0,47 & $-0,51 *$ & $-0,29 *$ & $0,45^{*}$ & $0,45^{*}$ & 1 \\
\hline
\end{tabular}

$* \mathrm{p}<0,01$

Fonte: autores.

Quanto à percepção de suporte organizacional, os resultados mostram que o fator ascensão, promoção e salários apresentou a pontuação média mais baixa, com valor de 1,63 (DP = 0,47) em uma escala de 1 a 5. Quanto maior é a pontuação, melhor é a percepção de suporte, com exceção do fator sobrecarga de trabalho, cuja pontuação elevada indica a falta de suporte. A média baixa do fator ascensão, promoção e salários, aliada ao baixo desvio-padrão, indica que os servidores do PGPE participantes do estudo nunca ou raramente percebem práticas e ações do órgão voltadas para a retribuição financeira e oportunidades de desenvolvimento profissional. A segunda pontuação média mais baixa foi em relação à gestão do desempenho ( $M=2,65$; $D P=0,67)$, indicando que apenas raramente ou algumas vezes apenas são percebidas práticas para valorização de novas ideias, atualização dos colaboradores e estabelecimento de metas claras. As práticas de suporte mais presentes na organização, segundo avaliação dos respondentes, consistem no suporte material $(M=3,16$; $D P=0,62)$, revelando que o órgão disponibiliza, com frequência moderada, os recursos necessários para a realização das tarefas laborais.

Em relação às correlações, foram observadas associações significativas entre a intenção de rotatividade e todas as dimensões de suporte organizacional. Quanto 
maior é a percepção de suporte organizacional, menor é a intenção de rotatividade. Ascensão, promoção e salários, que constituiu a dimensão de suporte avaliada mais negativamente pelos respondentes, apresentou a correlação mais forte com a intenção de rotatividade $(r=0,51)$. Sobrecarga de trabalho, por sua vez, é o fator de suporte que apresenta associação mais fraca com a intenção de rotatividade $(r=0,28)$.

A fim de explorar os dados, verificaram-se possíveis associações da idade, tempo de trabalho na organização, sexo, cargo e escolaridade do servidor com sua intenção de rotatividade. Apenas idade e tempo de trabalho na organização apresentaram associações significativas com a variável dependente: $r=-0,53(p<0,01)$ e $r=-0,50$ $(p<0,01)$, respectivamente. Quanto mais jovem é o servidor e menor é o tempo de trabalho no órgão, maior é o desejo de deixar a organização.

Os resultados das correlações entre as variáveis independentes e a variável dependente demonstram que existem associações significativas entre todos os fatores de suporte e a intenção de rotatividade. Além disso, duas variáveis pessoais dos respondentes apresentaram associações significativas com a intenção de rotatividade. Partiu-se, assim, para a condução de regressão múltipla hierárquica para testar a força de cada variável em um modelo preditivo da intenção de rotatividade. Idade e tempo na organização foram inseridos no primeiro bloco e, no segundo bloco, foram inseridos os fatores de suporte organizacional.

A Tabela 2 apresenta os resultados encontrados por meio da regressão. No primeiro passo, as variáveis sociodemográficas idade e tempo na organização explicaram 39\% da variância da intenção de rotatividade $\left(R^{2}\right.$ ajustado $=0,39$; $p<0,001)$. Depois do segundo passo, em que os fatores de suporte organizacional foram adicionados ao modelo, o valor de $R^{2}$ ajustado sofreu incremento de $0,17\left(R^{2}\right.$ ajustado $=0,56 ; p<0,001)$.

Tabela 2 - Resultados da regressão hierárquica para intenção de rotatividade

\begin{tabular}{|c|c|c|c|}
\hline & $R^{2}$ aj & $\Delta R^{2}$ aj & Beta \\
\hline $\begin{array}{l}\text { Passo 1: Idade } \\
\text { Tempo na organização }\end{array}$ & $0,39 *$ & & $\begin{array}{l}-0,42^{*} \\
-0,32^{*}\end{array}$ \\
\hline $\begin{array}{l}\text { Passo 2: Idade } \\
\qquad \begin{array}{l}\text { Tempo na organização } \\
\text { Ascensão, promoção e salários } \\
\text { Gestão de desempenho } \\
\text { Suporte material } \\
\text { Sobrecarga de trabalho }\end{array}\end{array}$ & $0,56^{*}$ & $0,16^{*}$ & $\begin{array}{l}-0,32^{*} \\
-0,33^{*} \\
-0,43^{*} \\
\text { ns } \\
\text { ns } \\
\text { ns }\end{array}$ \\
\hline
\end{tabular}

$* p<0,001$

ns = não significativo

Fonte: autores. 
O modelo final da regressão foi significativamente diferente de zero $\left(\mathrm{F}_{6,104}=\right.$ 22,849; $p<0,001)$ e composto pelas variáveis suporte para ascensão, promoção e salários $(\beta=-0,43)$; tempo na organização $(\beta=-0,33)$; e idade $(\beta=-0,32)$. Juntas, essas três variáveis explicaram $56 \%$ da variância da intenção de rotatividade. 0 suporte para ascensão, promoção e salários, por sua vez, foi a variável com maior poder preditivo no modelo final. A relação entre as variáveis apontadas e a intenção de rotatividade foi negativa, indicando que quanto menores são a percepção de suporte, a idade e o tempo na organização, maior é o desejo de deixar o órgão.

\section{Discussão}

Os resultados referentes às análises descritivas das variáveis indicam, em primeiro lugar, que os servidores participantes da pesquisa apresentam um forte desejo de deixar o órgão, pensando nisso frequentemente ou sempre. Tal resultado vai ao encontro de achados do MPOG (2012) e Verleun (2008) sobre a alta rotatividade no serviço público brasileiro, especialmente na esfera executiva da administração pública. Além disso, os resultados suportam a importância de organizações públicas realizarem uma estimativa periódica das intenções de comportamento de saída dos servidores e de suas possíveis causas, conforme propõe Mobley (1992).

Em segundo lugar, os resultados descritivos revelam as percepções que servidores pertencentes ao PGPE têm a respeito do órgão público investigado. Ficou evidenciada a percepção negativa sobre as práticas voltadas à retribuição financeira e às oportunidades de desenvolvimento e ascensão profissional no órgão, as quais são percebidas como quase inexistentes. Ademais, constatou-se que os respondentes raramente percebem práticas organizacionais voltadas à valorização de novas ideias e atualização dos servidores diante das novas tecnologias e processos de trabalho. De forma geral, observa-se que a retribuição do órgão aos esforços do servidor, em termos de valorização, recompensas e gerenciamento do desempenho, é percebida de forma bastante negativa e que, além disso, existe um forte desejo de deixar o órgão em um futuro próximo. Tais achados sugerem que as organizações conseguem atrair profissionais para o serviço público (CASTELAR et al., 2010), mas não conseguem, necessariamente, mantê-los.

Quanto à influência das dimensões do suporte organizacional sobre a intenção de rotatividade, os resultados do impacto das práticas de ascensão, promoção e salários convergem com achados de pesquisas anteriores. Ramlall (2003), por exemplo, verificou que o número de promoções obtidas pelo trabalhador é uma variável determinante na intenção de deixar a organização. Ferreira e Freire (2001), por sua vez, destacam que as causas da rotatividade são múltiplas, mas a política de benefícios e as oportunidades de progresso profissional da organização têm 
sido frequentemente associadas à rotatividade. Segundo Verleun (2008), o servidor possui expectativas de desenvolvimento profissional, que incluem a velocidade de progressão funcional, o salário atribuído ao cargo e os benefícios concedidos comparativamente às demais carreiras disponíveis no mercado de trabalho.

O servidor, de acordo com Verleun (2008), constantemente mapeia e avalia as diversas oportunidades existentes no mercado de trabalho. Quando suas expectativas não são atendidas e a retribuição da organização ao esforço individual é percebida negativamente, podem surgir comportamentos oportunistas associados ao trabalho. Por exemplo, o servidor pode começar a executar uma agenda particular paralela à agenda institucional, deixando de desenvolver tarefas laborais para estudar para outro concurso, entre outros comportamentos prejudiciais à organização. Em última instância, seria observada a evasão do servidor para outras carreiras e órgãos, avaliados mais positivamente quanto às políticas de práticas de valorização, recompensas e progressão profissional.

As variáveis sociodemográficas, como idade e tempo de trabalho na organização, não têm sido apontadas como importantes preditores da rotatividade. Neste estudo, as referidas variáveis apresentaram correlações significativas com intenção de rotatividade e compuseram o modelo preditivo do fenômeno. Os resultados convergem com dados do MPOG (2012), segundo os quais muitos são os candidatos aprovados em concurso público que não se apresentam para a nomeação ou que tomam posse e, em seguida, pedem exoneração ainda dentro do prazo de validade do concurso.

Pessoas mais jovens podem apresentar expectativas de progressão, reconhecimento e valorização que, de acordo com as políticas e práticas organizacionais, estariam distantes de serem alcançadas. Com baixa idade e alocado no nível mais baixo da carreira referente ao cargo ocupado, estudar para outro concurso ou concorrer a outra vaga de emprego no mercado, iniciando uma carreira com melhores possibilidades de desenvolvimento e progressão pode parecer uma boa opção ao jovem servidor. Além disso, pode-se esperar que, com o passar do tempo, as pessoas tomem como seus alguns valores organizacionais e desenvolvam identificação com os objetivos da organização onde se inserem. Uma das abordagens presentes na literatura sobre socialização organizacional propõe que os indivíduos são sujeitos de um processo por meio do qual desenvolvem sua própria personalidade e, simultaneamente, apropriam-se dos costumes e valores sociais de seu contexto sócio-histórico (Borges; Albuquerque, 2004).

Conforme despende seu tempo trabalhando na mesma organização, é possível que as metas de vida do indivíduo e sua própria avaliação sobre suas expectativas e oportunidades aproximem-se do funcionamento, valores e metas organizacionais. 
Avaliações e metas pessoais vão se tornando compatíveis com o contexto organizacional. É possível que trabalhadores mais antigos na organização vivenciem maior compatibilidade entre interesses individuais e o dia a dia organizacional, apresentando menor desejo de deixar seu posto de trabalho. Vale ressaltar ainda que, na maior parte das organizações públicas, o tempo de serviço ainda é o critério mais importante para o desenvolvimento na carreira, dado que "no modelo de progressão funcional atual, a curva de ascensão é linear, sem diferenciação de perfil entre os níveis profissionais intrafaixas e descasada da avaliação de desempenho do servidor" (VERLEUN, 2008, p. 10).

Diante dos resultados encontrados neste estudo, sugere-se a adoção de medidas e ações pela Coordenação-Geral de Recursos Humanos (CGRH), em conjunto com as diversas secretarias e departamentos do órgão, no intuito de aumentar a percepção de suporte organizacional como forma de minimizar a intenção de rotatividade dos servidores efetivos de seus quadros.

Em relação às políticas de ascensão, promoção e salários, apesar de a CGRH ter a atuação limitada à aplicação das normas estabelecidas pela Secretaria de Gestão Pública (Segep) do Ministério do Planejamento, Orçamento e Gestão, poderia ser discutida e estabelecida, por exemplo, uma política de incentivos à ocupação de cargos de direção e chefia por servidores pertencentes ao quadro do órgão em detrimento de pessoas alheias à instituição, conforme propõe Veleun (2008), consoante ao Decreto $n$ ㅇ 5.497, de 21 de julho de 2005, o qual dispõe sobre o provimento de cargos em comissão do grupo-direção e assessoramento superiores (DAS), níveis 1 a 4, por servidores de carreira, no âmbito da administração pública federal (BRASIL, 2005) .

Ações no sentido de profissionalizar a ocupação de cargos e funções comissionadas, segundo Verleun (2008), aumentariam a percepção dos servidores acerca das oportunidades de desenvolvimento profissional e da existência de políticas de valorização do mérito para ocupação de tais cargos e funções. A autora ainda afirma que tal ação só deve funcionar se a instituição eliminar a presença de agentes estranhos à carreira e iniciar um longo processo de aculturação das práticas anteriores e de motivação de seus servidores no desenvolvimento de um corpo funcional realmente comprometido com os objetivos estratégicos da instituição e de uma organização que valoriza e se compromete com seus servidores.

De um modo mais amplo, caberia ao Governo Federal repensar a forma de progressão funcional linear à qual os seus servidores estão submetidos, conforme propõe Verleun (2008). No modelo atual, todos os servidores chegarão ao topo de suas carreiras no final de um determinado período, independentemente do esforço individual, competências profissionais, resultados de desempenho ou do valor agregado resultante de cada servidor para a instituição. Consequentemente, esse 
modelo pode gerar desmotivação e favorecer o surgimento de comportamentos incompatíveis com os objetivos da organização, pois a suposição de que todos merecem estar no topo desconsidera a natureza competitiva do trabalhador (VERLEUN, 2008). A referida autora ainda destaca que o modelo atual é desvantajoso tanto para o Estado, pois há o custo de realização de novos concursos para cobrir evasões recorrentes, quanto para os servidores, que se sentem desmotivados e passam a mapear constantemente carreiras que lhes ofereçam melhores oportunidades de progressão funcional.

A adoção de medidas e ações estratégicas pelo governo, no sentido de minimizar as disparidades de remuneração e benefícios oferecidos entre cargos similares ou de função idêntica dentro de uma mesma estrutura de poder republicano e até dentro de um mesmo órgão, também pode ser apontada como fundamental para a redução da intenção de rotatividade dos servidores, visto que os resultados encontrados evidenciam forte correlação entre o fator de ascensão, promoção e salários e o desejo de deixar o emprego (OLIVEIRA, 2009). Ações nesse sentido beneficiariam os servidores, uma vez que afetariam diretamente suas percepções acerca da valorização recebida da organização em retribuição aos esforços despendidos na realização das tarefas, e os cidadãos, que usufruem dos serviços prestados por tais servidores. Trabalhadores competentes, valorizados e satisfeitos tendem a ter um desempenho melhor e poderiam influenciar positivamente a excelência dos serviços prestados pelos órgãos (GOMES, 2008).

Considerando que uma percepção favorável de suporte pode gerar um maior esforço do empregado para atingir os objetivos da organização (EISENBERGER et al., 1986), faz-se fundamental a adoção de medidas no intuito de aumentar a percepção dos servidores públicos sobre a valorização recebida da organização em retribuição aos esforços despendidos na realização do trabalho.

\section{Conclusões}

O objetivo principal deste trabalho foi testar a influência do suporte organizacional percebido sobre a intenção de rotatividade de servidores públicos pertencentes ao Plano Geral de Cargos do Poder Executivo (PGPE) de um órgão da administração pública federal. Pode-se afirmar que o objetivo proposto foi alcançado. Resumidamente, os achados revelaram que os servidores têm um alto desejo de deixar a organização e percebem negativamente o suporte organizacional voltado à ascensão, promoção e salários e gestão do desempenho. Além disso, quanto menor é a percepção de suporte organizacional, maior é a intenção de rotatividade.

Contribuições desta pesquisa podem ser apontadas no âmbito institucional, acadêmico e social. No âmbito institucional, esta pesquisa produziu um diagnóstico 
acerca do suporte organizacional percebido pelos servidores públicos do órgão investigado e da sua intenção de deixar a organização em um futuro próximo. Com base nos resultados encontrados, a Coordenação-Geral de Recursos Humanos, juntamente com as demais secretarias e departamentos desse órgão público, poderão pensar estratégias para redução da evasão voluntária, buscando a adequação de suas práticas e políticas organizacionais, como aquelas relacionadas a oportunidades de ascensão, promoção e salários dos seus servidores.

Além disso, este estudo apresenta às organizações públicas, que enfrentam o problema da rotatividade, uma sugestão metodológica de como tratar, investigar e acompanhar o fenômeno. A avaliação constante da intenção de rotatividade e a mensuração de percepções dos servidores sobre as práticas da organização despontam como uma alternativa para os gestores. Sugere-se, portanto, a realização de pesquisas de forma periódica, a fim de mensurar e avaliar os níveis de percepção das variáveis estudadas, possibilitando um planejamento mais efetivo das políticas de gestão de pessoas, uma vez que o caráter transversal do trabalho em tela reflete dados relativos apenas a determinado período de tempo. Ações nesse sentido permitiriam mapear o comportamento de seus colaboradores em longo prazo e, consequentemente, atuar de forma mais direta nos problemas originados pela ocorrência da rotatividade voluntária.

No âmbito acadêmico, esta pesquisa contribui para preencher uma lacuna da literatura. Apesar de autores diversos convergirem sobre a importância do tema, poucos estudos empíricos foram encontrados no contexto das organizações públicas brasileiras. Essas organizações apresentam peculiaridades legais, culturais e gerenciais que dificultam a generalização de achados do contexto de empresas privadas para compreensão da rotatividade de servidores públicos. Por fim, no âmbito social, é esperado que os resultados levem a reflexões e discussões sobre políticas e práticas organizacionais que favoreçam o trabalho do servidor e, consequentemente, os serviços prestados aos cidadãos.

Apesar das contribuições, é possível apontar como limitação da pesquisa a representatividade da amostra investigada. Em relação à própria organização, mesmo com o envio do questionário a todos os servidores, apenas 32,18\% deles responderam e retornaram. Esses respondentes, portanto, não foram escolhidos aleatoriamente. Em relação aos servidores públicos, também não é possível generalizar os resultados às outras organizações.

Outro fator que deve ser considerado é a utilização do e-mail institucional dos funcionários para o envio do questionário. Destaca-se que, em muitos setores da organização investigada, não há o hábito de se utilizar o correio eletrônico institucional, o que dificultou o conhecimento de alguns servidores sobre a 
realização desta pesquisa, minimizando, assim, o número final de respondentes e, consequentemente, o poder de generalização deste estudo.

Ao expor a importância da realização de estudos sobre a percepção de suporte organizacional e intenção de rotatividade e explorar tal temática, esta pesquisa poderá incentivar o desenvolvimento de novas investigações, tanto acerca das variáveis focalizadas, como de outros fenômenos que possam influenciar de algum modo a intenção de funcionários deixarem a organização para a qual trabalham em algum momento futuro.

Recomenda-se aos pesquisadores interessados no tema que investiguem de forma mais detalhada os antecedentes da intenção de rotatividade, introduzindo variáveis individuais, como metas pessoais e comprometimento, e variáveis ligadas ao contexto socioeconômico em que se insere o indivíduo. Pesquisas futuras poderiam investigar ainda a própria rotatividade, por meio de estudos longitudinais, não se restringindo à intenção do comportamento.

Por fim, a realização de pesquisas envolvendo amostras representativas de todos os servidores do Governo Federal pertencentes ao Plano Geral de Cargos do Poder Executivo desponta como demanda relevante, pois poderia fornecer um diagnóstico mais completo das percepções que tais colaboradores têm sobre os construtos abordados. Os dados poderiam ser utilizados para auxiliar no planejamento e execução de políticas de recursos humanos voltadas, por exemplo, para a melhoria dos planos de carreiras de tais colaboradores.

\section{Referências bibliográficas}

ABRUCio, Fernando L. Trajetória recente da gestão pública brasileira: um balanço crítico e a renovação da agenda de reformas. Revista de Administração Pública, Rio de Janeiro, Edição Especial Comemorativa, p. 67-86, 2007.

AlLEN, David G.; SHANOCK, Linda L. Perceived organizational support and embeddedness as key mechanisms connecting socialization tactics to commitment and turnover among new employees. Journal of Organizational Behaviour, v. 34, n. 3, p. 350-369, 2013.

Borges, Lívia O.; Albuquerque, Francisco J. B. Socialização organizacional. In: ZANELLI, José C.; Borges-ANDRADE, Jairo E.; BAStos, Antônio V. B. (Orgs.). Psicologia, organizações e trabalho no Brasil. Porto Alegre: Artmed, 2004. p. 331-356.

BRASIL. Constituição (1988). Constituição da República Federativa do Brasil. Brasília, DF: Senado, 1988.

Decreto no 5.497, de 21 de julho de 2005. Dispõe sobre o provimento de cargos em comissão do Grupo-Direção e Assessoramento Superiores - DAS, níveis 1 a 4, por servidores de carreira, no âmbito da administração pública federal. Diário Oficial da União, Brasília, DF, 22 jul. 2005, p.5. 
Lei no 8.112, de 11 de dezembro de 1990. Dispõe sobre o regime jurídico dos servidores públicos civis da União, das autarquias e das fundações públicas federais. Diário Oficial da União, Brasília, DF, 12 dez. 1990. Seção 1, p.1.

CAILLIER, James G. I want to quit: a closer look at factors that contribute to the turnover intentions of State government employees. State and Local Government Review, v. 43, n. 2, p. 110-122, 2011.

CAMPos, Cláudia V. A.; MALIK, Ana M. Satisfação no trabalho e rotatividade dos médicos do Programa de Saúde da Família. Revista de Administração Pública, Rio de Janeiro, v. 42. n. 2, p. 347-368, 2008.

CAstelar, Ivan; Veloso, Alexandre W. A.; FerReira, Roberto T.; SoARES, Ilton. Uma análise dos determinantes de desempenho em um concurso público. Economia Aplicada, v. 14, n. 1, p. 81-98, 2010.

DE GIETER, Sara; HofmANS, Joeri. How reward satisfaction affects employees' turnover intentions and performance: an individual differences approach. Human Resource Management Journal, v. 25, n. 2, p. 200-216, 2015.

Departamento INTERSINDical de Estatística e Estudos Socioeconômicos (DieESE). Rotatividade e flexibilidade no mercado de trabalho. São Paulo: DIEESE, 2011. Disponível em: < http://www.dieese.org.br/livro/2011/livroRotatividade11.pdf>. Acesso em: 24 mar. 2013.

Eisenberger, Robert; Huntigton, Robin; Hutchison, Steven.; SowA, Debora. Perceived organizational support. Journal of Applied Psychology, v. 71, n. 3, p. 500507, 1986.

EISENBERGER, Robert et al. Perceived supervisor support: contributions to perceived organizational support and employee retention. Journal of Applied Psychology, vol. 87, n. 3, p. 565-573, 2002.

FARIAS, Pedro. C. L. de; GAETANI, Francisco. A política de recursos humanos e a profissionalização da administração pública no Brasil do século XXI: um balanço provisório. CONGRESO INTERNACIONAL DEL CLAD SOBRE LA REFORMA DEL ESTADO Y DE LA ADMINISTRACIÓN PÚBliCA, 7., 2002, Lisboa, Portugal.

FAUL, Franz; ERDEFELDER, Edgar; LANG, Albert-Georg; BuChNER, Axel. G*Power 3: a flexible statistical power analysis program for the social, behavioral, and biomedical sciences. Behaviour Research Methods, v. 39, n. 2, p. 175-191, 2007.

FERreIRA, Mário C.; FreIRE, Odaléia N. Carga de trabalho e rotatividade na função de frentista. Revista de Administração Contemporânea, Curitiba, v. 5, n. 2, p. 175200, 2001.

FerreirA, Maria L. C. B.; Siqueira, Mirlene M. M. Antecedentes de intenção de rotatividade: estudo de um modelo psicossocial. Organizações em Contexto, São Paulo, v. 1, n. 2, p. 47-67, 2005.

GoMES, Nanci. F. A subjetividade do servidor público constituída na relação com o Estado e a sociedade. Psicologia para América Latina, México, n. 15, 2008.

HAUSKNECHT, John P.; RoddA Julianne; HowARD, Michael J. Targeted employee retention: performance-based and job-related differences in reported reasons for staying. Human Resource Management, v. 48, n. 2, p. 269-288, 2009. 
JúNIOR, José C. C.; NogueIRA, Roberto P. Ocupação no setor público brasileiro: tendências recentes e questões em aberto. Revista do Serviço Público, Brasília, v. 62, n. 3, p. 237-260, 2011.

KIM, Soonhee. Factors affecting State government information technology employee turnover intentions. The American Review of Public Administration, v. 35, n. 2, p. 137-56, 2005.

LEWIS, Gregory B.; FRANK, Sue A. Who wants to work for government? Public Administration Review, v. 62, n. 4, p. 395-404, 2002.

Medeiros, Cássia R. G.; JunqueIRA, Álvaro G. W.; SCHWingel, Glademir I. C.; JUNGLES, Lúcia A. P.; SALDANHA, Olinda M. F. L. A rotatividade de enfermeiros e médicos: um impasse na implementação da Estratégia de Saúde da Família. Ciência e Saúde Coletiva, v. 15, n.1, p. 1521-1531, 2010.

Ministério do Planejamento, Orçamento e Gestão (MPOG). Boletim Estatístico de Pessoal, v. 17, n. 190, fevereiro de 2012. Disponível em: <http://www.servidor. gov.br/publicacao/boletim estatistico/bol estatistico 12/Bol190 Fev2012.pdf>. Acesso em: 24 mar. 2012.

MoBLEY, William. H. Turnover: causas, consequências e controle. Porto Alegre: Ortiz, 1992.

MotTA, Paulo. R. A modernização da administração pública brasileira nos últimos 40 anos. Revista de Administração Pública, Rio de Janeiro, Edição Especial Comemorativa, p. 87-96, 2007.

MoYNIHAN, Donald P.; LANDUYT, Noel. Explaining turnover intention in State government: examining the roles of gender, life cycle, and loyalty. Review of Public Personnel Administration, v. 28, n. 2, p. 120-43, 2008.

Organização para a COOPERAÇÃo e DesenVolvimento ECONÔMico (OCDE). Avaliação da gestão de recursos humanos no Governo Federal - Relatório da OCDE: Brasil 2011. Brasília: OCDE, MPOG, 2011.

OliveirA, Petter R.; TristÃo, Rosana. M.; NeIVA, Elaine R. Burnout e suporte organizacional em profissionais de UTI-Neonatal. Educação Profissional: Ciência e Tecnologia, Brasília, v. 1, n. 1, p. 27-37, 2006.

OliveirA, Cézar T. P. A concentração de renda pública brasileira. Revista Querubim, Ano 5, n. 9, p. 23-28, 2009.

OliveirA-CAstro, Gardênia A.; PIlATI, Ronaldo; Borges-AndRAde, Jairo E. Percepção de suporte organizacional: desenvolvimento e validação de um questionário. Revista de Administração Contemporânea, Curitiba, v. 3, n. 2, p. 29-51, 1999.

PAschoal, Tatiane; TORRES, Cláudio V.; PORTo, Juliana. B. Felicidade no trabalho: relações com suporte organizacional e suporte social. Revista de Administração Contemporânea, Curitiba, v. 14, n. 6, p. 1054-1072, 2010.

PERRY, James L. Measuring public service motivation: an assessment of construct reliability and validity. Journal of Public Administration Reserach and Theory, v. 6, n. 1, p. 5-24, 1996. 
Perry, James L.; HondegheM, Annie; WISE, Lois R. Revisiting the motivational basis of public service: twenty years of research and a agenda for the future. Public Administration Review, v. 70, n.5, p. 681-690, 2010.

RAMLALL, Sunil. Managing employee retention as a strategy for increasing organizational competitiveness. Applied H. R. M Research, v. 8, n. 2, p. 63-72, 2003.

REGTS, Gerdien; MollemAN, Eric. To leave or not to leave: when receiving interpersonal citizenship behavior influences an employee's turnover intention. Human Relations, v. 66, n. 2, p. 193-218, 2012.

RHOADES, Linda; EISENBERGER, Robert. Perceived organizational support: a review of the literature. Journal of Applied Psychology, v. 87, n. 4, 698-714, 2002.

SiqueIRA, Mirlene M. M.; Gomide Jr, Sinésio; MARques, Tania M.; Moura, Olga I. Um modelo pós-cognitivo para intenção de rotatividade: antecedentes afetivos e cognitivos. Congresso INTERAMericano de Psicologia, 36., 1997, São Paulo. [Resumo]

TAmayo, Maurício R.; PInheiro, F. A.; Tróccoli, Bartholomeu T.; PAZ, Maria. G. T. Construção e validação da escala de suporte organizacional percebido (ESOP). [Resumo]. Anais da Reunião Anual da SBPC, 52, Brasília, 2000.

VANDENABEele, Wouter. Toward a public administration theory of public service motivation: an institutional approach. Public Management Review, v. 9, n. 4, p. 545-56, 2007.

VANDENBERG, Robert J.; Nelson, Jodi. B. Disaggregating the motives underlying turnover intentions: when do intentions predict turnover behavior? Human Relations, v.52, p. 1313-1336, 1999.

VERLEUN, Julieta A. G. A teoria do consumidor e a teoria dos incentivos aplicadas a um plano de carreiras do serviço público brasileiro: uma abordagem sucinta. CoNGRESO INTERNACIONAL DEL CLAD SOBRE LA REFORMA DEL ESTADO Y DE LA ADMINISTRACIÓN PúBLICA, 13, nov. 2008, Buenos Aires, Argentina.

WINTERTON, Jonathan. A conceptual model of labour turnover and retention. Human Resource Development International, vol. 7, n. 3, p. 371-390, 2004.

YANG, Jung; TREADWAY, Darren C.; STEPINA, Lee P. Justice and politics: mechanisms for the underlying relationships of role demands to employees' satisfaction and turnover intentions. Journal of Applied Social Psychology, v. 43, n. 8, p. 1624-1635, 2013.

Larissa Coutinho Diógenes

Graduada em Administração pela Universidade de Brasília e pós-graduada em Gestão Pública pelo Instituto IMP de Ensino Superior. Atualmente é servidora pública do Ministério da Saúde. Contato: larissa_diogenes@hotmail.com

Tatiane Paschoal

Doutora em Psicologia Social, do Trabalho e das Organizações pela Universidade de Brasília. Realizou estágio de doutorado na Universidad Complutense de Madrid, Espanha. Atualmente, é Professora Adjunta do Departamento de Administração da Universidade de Brasília, Pesquisadora do Grupo de Estudos e Pesquisas sobre a Gestão de Pessoas na Administração Pública e colaboradora em projetos de pesquisa do Grupo de Pesquisa em Ergonomia Aplicada ao Setor Público (ErgoPublic). Contato: tatianepaschoal@gmail.com 


\section{Elaine Rabelo Neiva}

Doutora em Psicologia pela Universidade de Brasília. Realizou pós-doutorado na Universidade Columbia em Nova Iorque, EUA. Realizou estágio de doutorado na Universidad Complutense de Madrid, Espanha. Atualmente, é Professora Adjunta do Departamento de Administração da Universidade de Brasília e do Programa de Pósgraduação em Psicologia Social, do Trabalho e das Organizações. Coordenadora do Grupo de Pesquisa Inovare sobre Mudança Organizacional e Redes Sociais. Contato: elaine_neiva@uol.com.br

\section{Pedro Paulo Murce Meneses}

Doutor e Mestre em Psicologia pela Universidade de Brasília. Professor Adjunto do Departamento de Administração e Pesquisador Credenciado do Programa de Pós-Graduação em Administração da Universidade de Brasília/ Faculdade de Administração, Contabilidade, Economia e Ciências da Informação e Documentação, onde atua, respectivamente, como docente e coordenador da área de pós-graduação stricto sensu de estudos organizacionais e gestão de pessoas. Coordenador do Grupo de Estudos e Pesquisas sobre a Gestão de Pessoas na Administração Pública Federal. Contato: pemeneses@yahoo.com.br 
